\title{
MATERIAL INVESTIGATION AND ANALYSIS USING CHARACTERISTIC X-RAY
}

\author{
GYUBUM OH and WONHO LEE \\ Department of Radiologic Science, Korea University \\ "Corresponding author. E-mail : wonhol@korea.ac.kr
}

Received December 30, 2009

Accepted for Publication May 19, 2010

The characteristic X-rays emitted from materials after gamma ray exposure was simulated and measured. A CdTe semiconductor detector and a ${ }^{57} \mathrm{Co}$ radiation source were used for energy spectroscopy. The types of materials could be identified by comparing the measured energy spectrum with the theoretical X-ray transition energy of the material. The sample composition was represented by the $\mathrm{K}_{\alpha 1}$-line (Siegbahn notations), which has the highest intensity among the characteristic X-rays of each atom. The difference between the theoretic prediction and the experimental result of K-line measurement was $<0.61 \%$ even if the characteristic X-rays from several materials were measured simultaneously. 2D images of the mixed materials were acquired with very high selectivity.

KEYWORDS : XRF, Characteristic X-ray, CdTe

\section{INTRODUCTION}

$\mathrm{X}$-ray fluorescence (XRF) analysis is a fast, reproducible, and non-destructive method that can be used to analyze multiple samples simultaneously. Therefore, it is one of the most common methods for obtaining qualitative and semi-quantitative information of the elements in a mixed sample. [1-2]

A vacancy is created when a photon of incoming radiation is absorbed completely by an atom, an electron in the inner shell is ejected from the atom, and the atom is left in an excited state. For stabilization, an electron in an outer shell falls into the vacancy and the difference in the energy status between the outer and the inner shell is converted to an Auger electron or a characteristic X-ray [2] (cf. Fig. 1). The XRF method measures the energy of the characteristic $\mathrm{X}$-ray depending on the atomic number of the exposed material.

This study examined single and multiple materials by $\mathrm{XRF}$, and the 2D distributions of the materials were obtained based on the XRF analysis.

\section{MATERIALS AND METHODS}

\subsection{Semiconductor detector}

$\mathrm{XRF}$ requires a detector with high energy resolution to accurately analyze a mixed material. Therefore, a CdTe detector, which can measure a high resolution energy spectrum without a bulky cooling system for room temperature operation, was chosen for the XRF measurements [3-6]. The detector (XR-100T-CdTe) and accessories (PX4: Digital Pulse processor, MCA, and Power Supply) were obtained from AMPTEK.

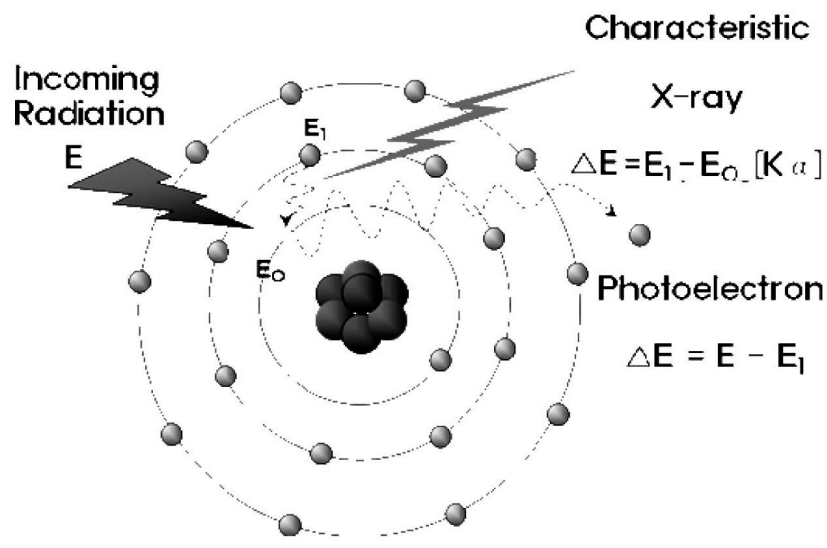

Fig. 1. The Process of the Characteristic X-ray Emission 


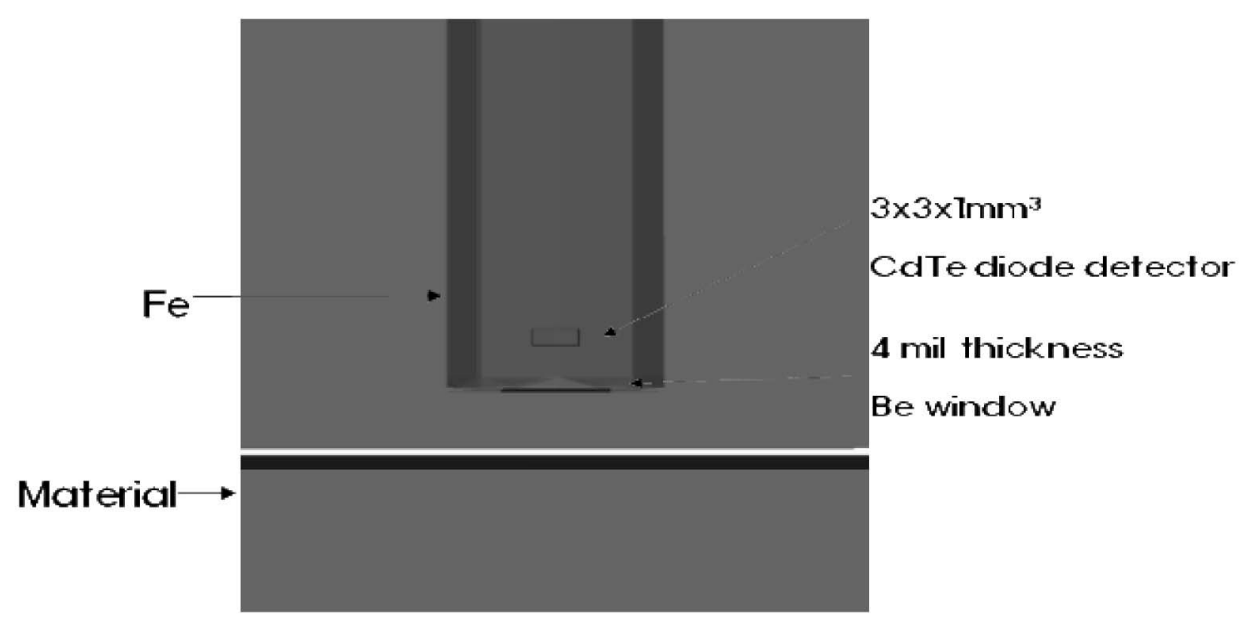

Fig. 2.The Simulation Plot using MCNP
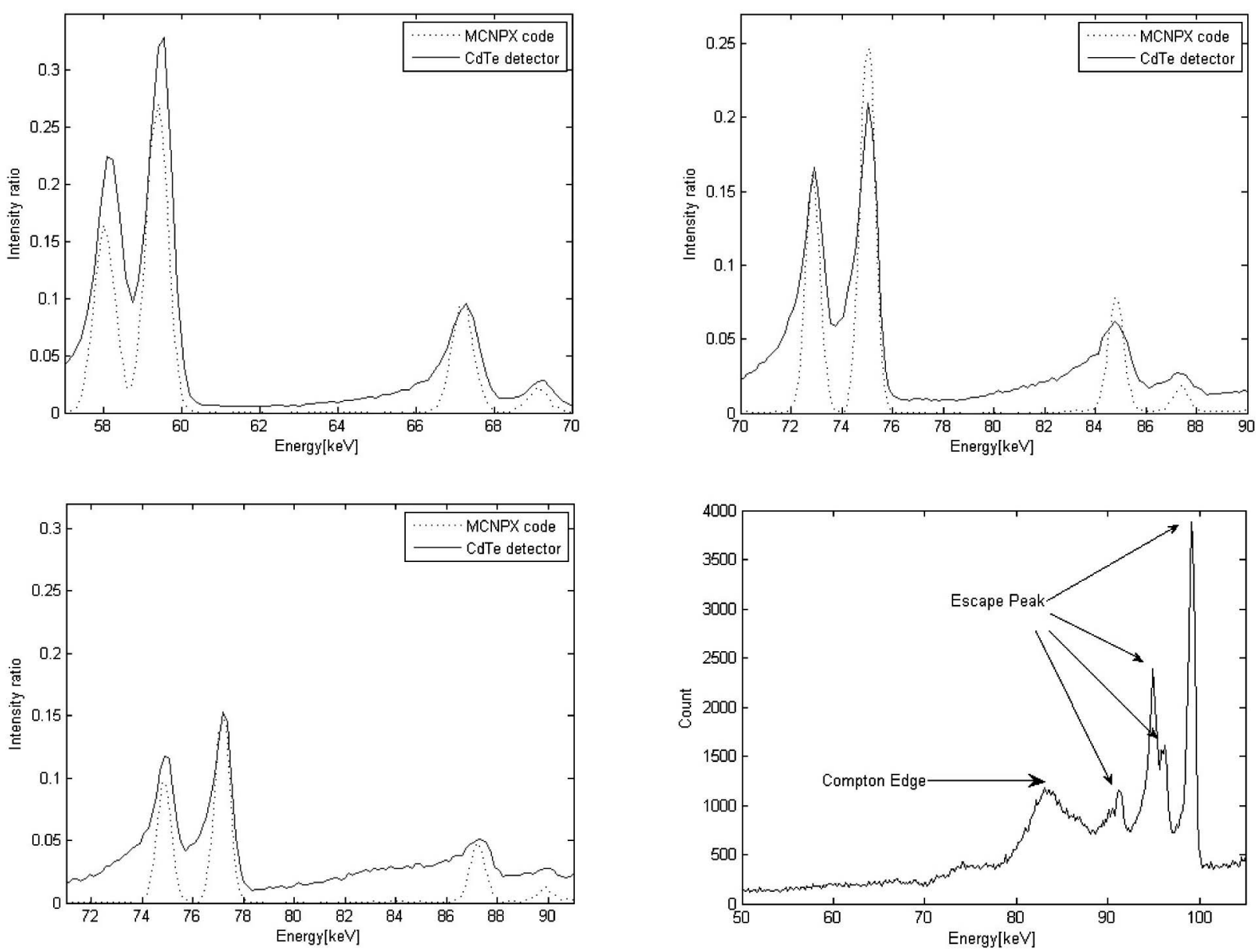

Fig. 3. XRF Spectra of a Single Material: (a) Tungsten, (b) Bismuth, (c) Lead, (d) and Escape Peaks and Compton Edge in a CdTe Detector 


\subsection{Isotope}

Photoelectric absorption can occur only if the photon energy is equal to or greater than the binding energy of the electron. XRF shows its maximum intensity when the photon energy is just above the K-edge of the sample element. Therefore, ${ }^{57} \mathrm{Co}$ (Eckert \& Zieger), whose radiation energy is $14 \mathrm{keV}(9.16 \%), 122 \mathrm{keV}(85.6 \%)$, and $136 \mathrm{keV}(10.68 \%)$, was used as the radiation source.

\subsection{Geometrical positioning and energy spectrum}

${ }^{57} \mathrm{Co}$ was placed between the CdTe detector and material (cf. Fig. 2). The radiation emitted directly from the ${ }^{57} \mathrm{Co}$ source was easily discriminated from the XRF radiation using the energy spectrum.

The FWHM parameters based on the observed energy broadening in the CdTe detector was applied to
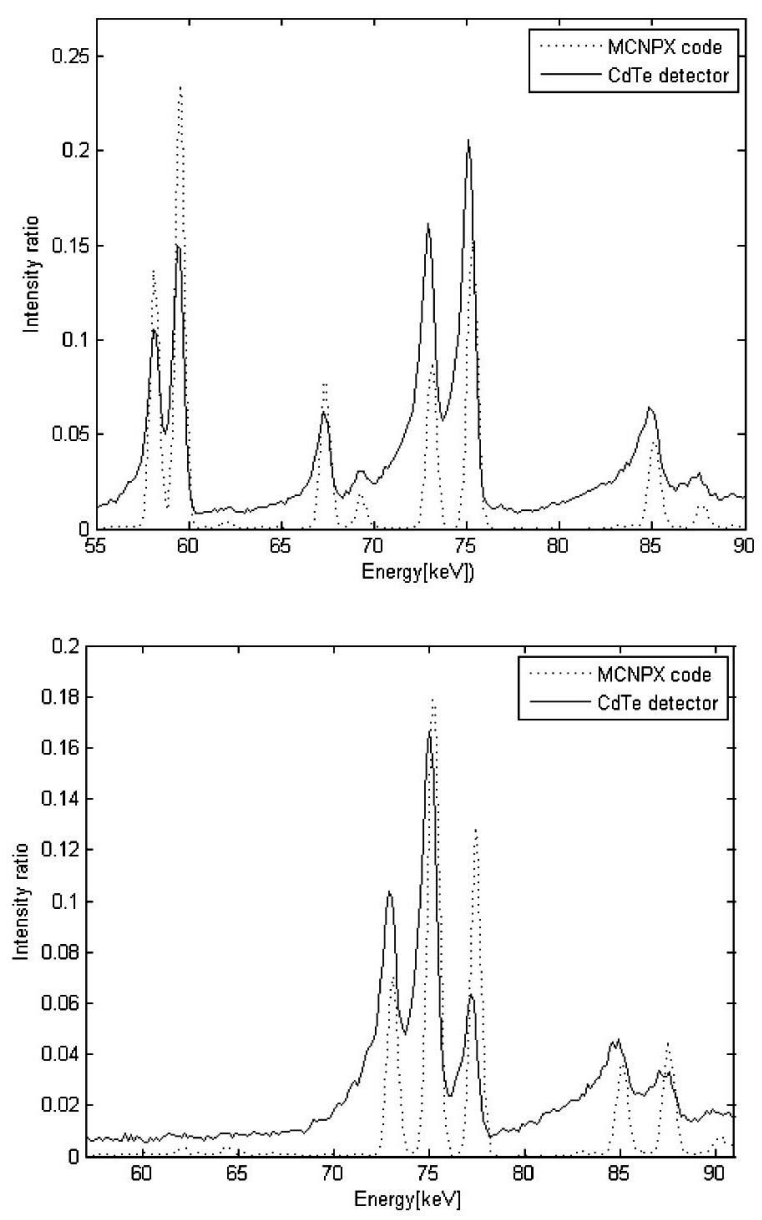

the MCNPX Monte Carlo simulation. The FWHMs of ${ }^{55} \mathrm{Fe},{ }^{57} \mathrm{Co},{ }^{109} \mathrm{Cd}$, and ${ }^{241} \mathrm{Am}$ radiation sources were measured to produce the following empirical formula:

$$
\mathrm{FWHM}=0.25433+1.3 \sqrt{\mathrm{E}+2.4832 \mathrm{E}^{2}}[\mathrm{keV}] .
$$

\section{RESULTS}

\subsection{Single material}

As shown in Figs. 3 and 4, the XRF spectrum of W, $\mathrm{Pb}$, and $\mathrm{Bi}$ were measured. The peaks observed by the experiment and calculated by the simulation were
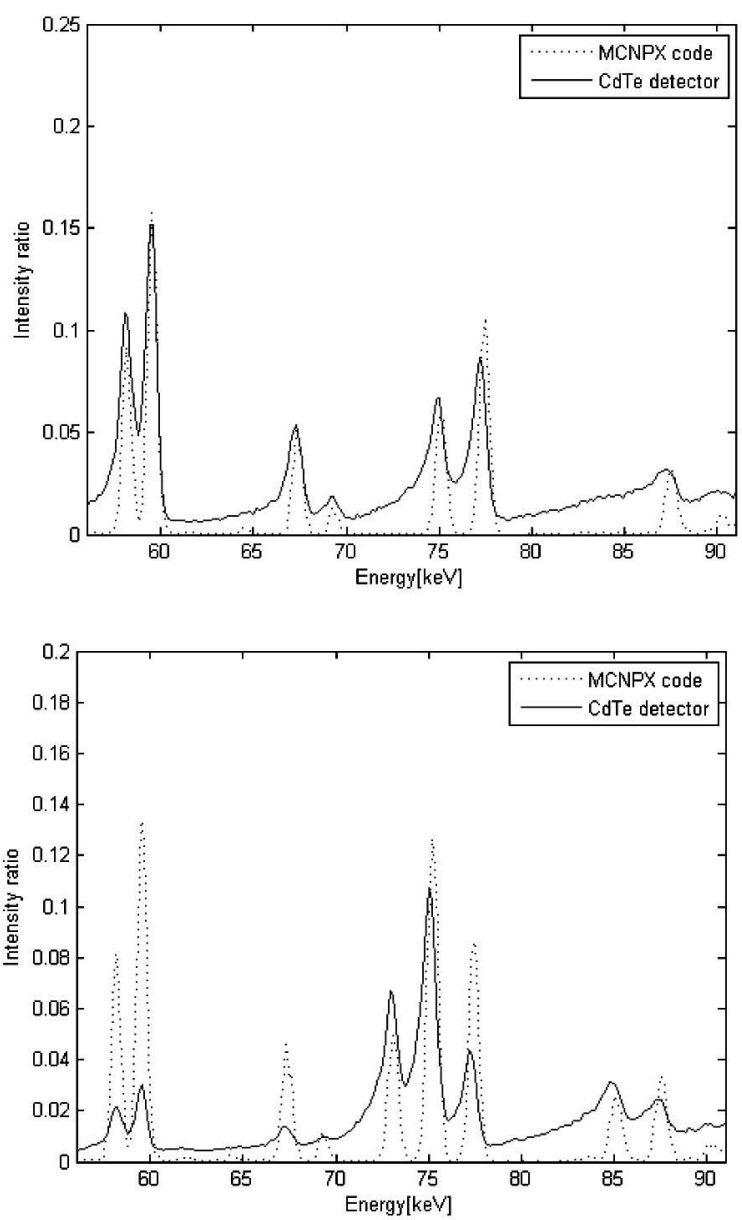

Fig. 4. XRF Spectra for Multiple Materials: (a) Tungsten and Lead, (b) Tungsten and Bismuth, (c) Lead and Bismuth, (d) Tungsten, and Lead and Bismuth 
compared with the theoretical X-ray transition energies. These peaks were confirmed to be the $\mathrm{K}_{\alpha 1}, \mathrm{~K}_{\alpha 2}, \mathrm{~K}_{\beta 1}$, and $\mathrm{K}_{\beta 2}$-lines allowed by the selection rules (cf. Table 1-8). The intensity of the $\mathrm{K}_{\alpha 1}$-line was the highest because the electron transition from the $\mathrm{L}$ to $\mathrm{K}$ shell was the most probable process among the transitions. The characteristic X-ray peaks as well as the escape peaks and Compton scattering were observed, as shown in Fig. 3 (d). There was also spectrum distortion due to the tail effect in the CdTe semiconductor detector, which was caused by the poor charge collection and relatively small mobility lifetime of the holes [7-8]. The tail effect was more severe for the higher energy X-ray peaks.

The average difference between the theoretical and simulation values for $\mathrm{W}$ was $0.044 \mathrm{keV}(0.07 \%)$ with a maximum difference of $0.088 \mathrm{keV}(0.15 \%)$. The average difference between the theoretical and simulation values for $\mathrm{Pb}$ was $0.079 \mathrm{keV}(0.1 \%)$ with a maximum difference of $0.135 \mathrm{keV}(0.18 \%)$. The average difference between the theoretical and simulation values for $\mathrm{Bi}$ was $0.097 \mathrm{keV}(0.12 \%)$ with a maximum difference of $0.147 \mathrm{keV}(0.12 \%)$.

The average difference between the theoretical and experimental values for $\mathrm{W}$ was $0.148 \mathrm{keV}(0.24 \%)$ with a maximum difference of $0.246 \mathrm{keV}(0.41 \%)$. The average difference between the theoretical and experimental values for $\mathrm{Pb}$ was $0.116 \mathrm{keV}(0.14 \%)$ with a maximum difference of $0.162 \mathrm{keV}(0.19 \%)$. The average difference

Table 1. Theoretical Transition Energies. (Unit, keV) [9-10]

\begin{tabular}{c|c|c|c|c}
\hline Atom & $\mathrm{K}_{\alpha 1}$-line & $\mathrm{K}_{\alpha 2}$-line & $\mathrm{K}_{\beta 1}$-line & $\mathrm{K}_{\beta 2}$-line \\
\hline${ }_{74} \mathrm{~W}$ & 59.318 & 57.981 & 67.245 & 69.102 \\
\hline${ }_{82} \mathrm{~Pb}$ & 74.970 & 72.806 & 84.940 & 87.362 \\
\hline${ }_{83} \mathrm{Bi}$ & 77.108 & 74.816 & 87.351 & 89.849 \\
\hline
\end{tabular}

Table 2. Energy Peak in Fig 3 (a) (Unit, keV)

\begin{tabular}{c|c|c|c|c|c}
\hline \multirow{2}{*}{ Atom } & Method & $\mathrm{K}_{\alpha 1}$-line & $\mathrm{K}_{\alpha 2}$-line & $\mathrm{K}_{\beta 1}$-line & $\mathrm{K}_{\beta 2}$-line \\
\hline \multirow{2}{*}{${ }_{74} \mathrm{~W}$} & CdTe & 59.564 & 58.081 & 67.308 & 69.285 \\
\cline { 2 - 6 } & MCNPX & 59.406 & 58.006 & 67.305 & 69.105 \\
\hline
\end{tabular}

Table 3. Energy Peak in Fig 3 (b) (Unit, keV)

\begin{tabular}{c|c|c|c|c|c}
\hline \multirow{2}{*}{ Atom } & Method & $\mathrm{K}_{\alpha 1}$-line & $\mathrm{K}_{\alpha 2}$-line & $\mathrm{K}_{\beta 1}$-line & $\mathrm{K}_{\beta 2}$-line \\
\hline \multirow{2}{*}{${ }_{82} \mathrm{~Pb}$} & CdTe & 75.053 & 72.911 & 84.778 & 87.250 \\
\cline { 2 - 7 } & MCNPX & 75.105 & 72.805 & 84.804 & 87.404 \\
\hline
\end{tabular}

Table 4. Energy Data in Fig 3 (c) (Unit, keV)

\begin{tabular}{c|c|c|c|c|c}
\hline \multirow{2}{*}{ Atom } & Method & $\mathrm{K}_{\alpha 1}$-line & $\mathrm{K}_{\alpha 2}$-line & $\mathrm{K}_{\beta 1}$-line & $\mathrm{K}_{\beta 2}$-line \\
\hline \multirow{2}{*}{${ }_{83} \mathrm{Bi}$} & $\mathrm{CdTe}$ & 77.196 & 74.888 & 87.250 & 90.053 \\
\cline { 2 - 7 } & $\mathrm{MCNPX}$ & 77.204 & 74.905 & 87.204 & 89.904 \\
\hline
\end{tabular}

Table 5. Energy Peak in Fig 4 (a). (Unit, keV)

\begin{tabular}{c|c|c|c|c|c}
\hline \multirow{2}{*}{ Atom } & Method & $\mathrm{K}_{\alpha 1}$-line & $\mathrm{K}_{\alpha 2}$-line & $\mathrm{K}_{\beta 1}$-line & $\mathrm{K}_{\beta 2}$-line \\
\hline \multirow{2}{*}{${ }_{74} \mathrm{~W}$} & CdTe & 59.399 & 58.081 & 67.308 & 69.450 \\
\cline { 2 - 7 } & MCNPX & 59.506 & 58.106 & 67.405 & 69.205 \\
\hline \multirow{2}{*}{${ }_{82} \mathrm{~Pb}$} & CdTe & 75.053 & 72.911 & 84.778 & 87.580 \\
\cline { 2 - 7 } & MCNPX & 75.305 & 73.105 & 85.204 & 87.804 \\
\hline
\end{tabular}


between the theoretical and experimental values for $\mathrm{Bi}$ was $0.116 \mathrm{keV}(0.14 \%)$ with a maximum of $0.204 \mathrm{keV}$ $(0.23 \%)$.

\subsection{Complex materials}

\subsubsection{Two different materials}

As shown in Figs. 4 (a) - (c), XRF was performed for a combination of two different materials among $\mathrm{W}, \mathrm{Pb}$, and $\mathrm{Bi}$. When their atomic numbers were largely different, such as $\mathrm{W} / \mathrm{Pb}$ or $\mathrm{W} / \mathrm{Bi}$, the energy peaks of each material could be clearly separated from each other. On the other hand, when the atomic number of the material was similar, such as $\mathrm{Pb}$ and $\mathrm{Bi}$, the XRF peaks overlapped, preventing material analysis.

The mean difference between the theoretical and simulation values for $\mathrm{W} / \mathrm{Pb}$ was $0.240 \mathrm{keV}(0.32 \%)$ with a maximum difference of $0.442 \mathrm{keV}(0.5 \%)$. The average difference between the theoretical and simulation values for $\mathrm{W} / \mathrm{Bi}$ was $0.221 \mathrm{keV}(0.29 \%)$ with a maximum difference of $0.396 \mathrm{keV}(0.51 \%)$. The average difference between the theoretical and simulation values for $\mathrm{Pb} / \mathrm{Bi}$ was $0.267 \mathrm{keV}(0.33 \%)$ with a maximum difference of $0.555 \mathrm{keV}(0.61 \%)$.

The average difference between the theoretical and experimental values for $\mathrm{W} / \mathrm{Pb}$ was $0.145 \mathrm{keV}(0.2 \%)$ with a maximum difference of $0.348 \mathrm{keV}(0.5 \%)$. The average difference between the theoretical and experimental values for $\mathrm{W} / \mathrm{Bi}$ was $0.128 \mathrm{keV}(0.18 \%)$ with a maximum difference of $0.246 \mathrm{keV}(0.41 \%)$. The average difference between the theoretical and experimental values for $\mathrm{Pb} / \mathrm{Bi}$ was $0.116 \mathrm{keV}(0.14 \%)$ with a maximum difference of $0.265 \mathrm{keV}(0.3 \%)$.

\subsubsection{Three different materials}

The average difference between the theoretical and simulation values for $\mathrm{W}$ was $0.169 \mathrm{keV}(0.27 \%)$ with a maximum difference of $0.288 \mathrm{keV}(0.48 \%)$. The average difference between the theoretical and simulation values

Table 6. Energy Peak in Fig 4 (b). (Unit, keV)

\begin{tabular}{c|c|c|c|c|c}
\hline \multirow{2}{*}{ Atom } & Method & $\mathrm{K}_{\alpha 1}$-line & $\mathrm{K}_{\alpha 2}$-line & $\mathrm{K}_{\beta 1}$-line & $\mathrm{K}_{\beta 2}$-line \\
\hline \multirow{2}{*}{${ }_{74} \mathrm{~W}$} & CdTe & 59.564 & 58.081 & 67.308 & 69.121 \\
\cline { 2 - 7 } & MCNPX & 59.506 & 58.106 & 67.405 & 69.205 \\
\hline \multirow{2}{*}{${ }_{83} \mathrm{Bi}$} & CdTe & 77.196 & 75.053 & 87.415 & 90.053 \\
\cline { 2 - 7 } & MCNPX & 77.504 & 75.005 & 87.504 & 90.304 \\
\hline
\end{tabular}

Table 7. Energy Peak in Fig 4 (c). (Unit, keV)

\begin{tabular}{c|c|c|c|c|c}
\hline \multirow{2}{*}{ Atom } & Method & $\mathrm{K}_{\alpha 1}$-line & $\mathrm{K}_{\alpha 2}$-line & $\mathrm{K}_{\beta 1}$-line & $\mathrm{K}_{\beta 2}$-line \\
\hline \multirow{2}{*}{${ }_{82} \mathrm{~Pb}$} & CdTe & 75.053 (overlapped peak) & 72.911 & 84.943 & 87.580 \\
\cline { 2 - 6 } & $\mathrm{MCNPX}$ & 75.205 (overlapped peak) & 73.105 & 85.004 & 87.504 (overlapped peak) \\
\hline \multirow{2}{*}{${ }_{83} \mathrm{Bi}$} & CdTe & 77.196 & 75.053 (overlapped peak) & 87.086 & 89.888 \\
\cline { 2 - 6 } & $\mathrm{MCNPX}$ & 77.404 & 75.205 (overlapped peak) & 87.504 (overlapped peak) & 90.404 \\
\hline
\end{tabular}

Table 8. Energy Peak in Fig 4 (d) (Unit, keV)

\begin{tabular}{|c|c|c|c|c|c|}
\hline Atom & Method & $\mathrm{K}_{\alpha 1}$-line & $\mathrm{K}_{\alpha 2}$-line & $\mathrm{K}_{\beta 1}$-line & $\mathrm{K}_{\beta 2}$-line \\
\hline \multirow{2}{*}{${ }_{74} \mathrm{~W}$} & CdTe & 59.564 & 58.246 & 67.308 & 69.285 \\
\hline & MCNPX & 59.606 & 58.106 & 67.305 & 69.305 \\
\hline \multirow{2}{*}{${ }_{82} \mathrm{~Pb}$} & CdTe & 75.053(overlapped peak) & 72.911 & 84.778 & 87.415(overlapped peak) \\
\hline & MCNPX & 75.205(overlapped peak) & 73.105 & 85.004 & 87.604(overlapped peak) \\
\hline \multirow{2}{*}{${ }_{83} \mathrm{Bi}$} & CdTe & 77.196 & 75.053(overlapped peak) & 87.415(overlapped peak) & 90.218 \\
\hline & MCNPX & 77.404 & 75.205 (overlapped peak) & 87.604(overlapped peak) & 90.404 \\
\hline
\end{tabular}


for $\mathrm{Pb}$ was $0.21 \mathrm{keV}(0.27 \%)$ with a maximum difference of $0.299 \mathrm{keV}(0.41 \%)$. The average difference between the theoretical and simulation values for $\mathrm{Bi}$ was $0.426 \mathrm{keV}(0.5 \%)$ with a maximum difference of $0.555 \mathrm{keV}(0.61 \%)$.

The average difference between the theoretical and experimental values for $\mathrm{W}$ was $0.189 \mathrm{keV}(0.31 \%)$ with a maximum difference of $0.265 \mathrm{keV}(0.45 \%)$. The average difference between the theoretical and experimental values for $\mathrm{Pb}$ was $0.101 \mathrm{keV}(0.13 \%)$ with a maximum difference OF $0.162 \mathrm{keV}(0.19 \%)$. The average difference between the theoretical and experimental values for bismuth was $0.229 \mathrm{keV}(0.26 \%)$ with a maximum difference of $0.369 \mathrm{keV}(0.41 \%)$.

The overlapping of the simulation and experimental peaks increased with an increasing number of elements in the mixed material, and, hence, the spectral uncertainties
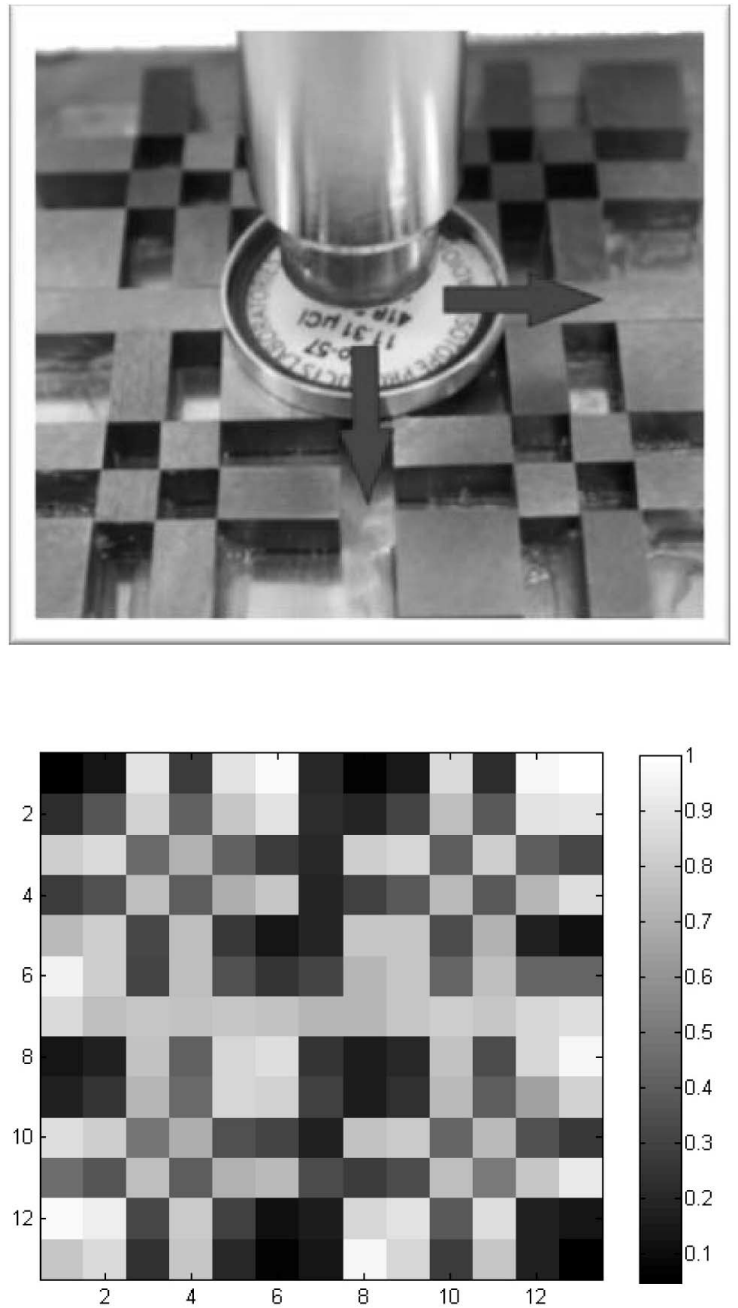

also increased with an increasing number of elements. The difference in XRF intensity between the experiment and simulation was caused by a discrepancy between the experiment and simulation conditions, such as the amount, density, and location of each element.

\subsection{Material distribution}

2D images of mixed materials were obtained by measuring the $\mathrm{K}_{\alpha 1}$-line intensity of each element. As shown in Fig. 5 (a), a detector and source scanned a mixed material in the orthogonal direction with a fixed timing step. The first material was patterned tungsten on top of a lead plate (cf. Fig. 5 (b)). The size of the entire pattern and that of the pattern unit was $6.5 \times 6.5 \times 0.5 \mathrm{~cm}^{3}$ and $0.5 \times 0.5 \times 0.5 \mathrm{~cm}^{3}$, respectively. As shown in Figs. 5 (c) and (d), the distributions of the two different
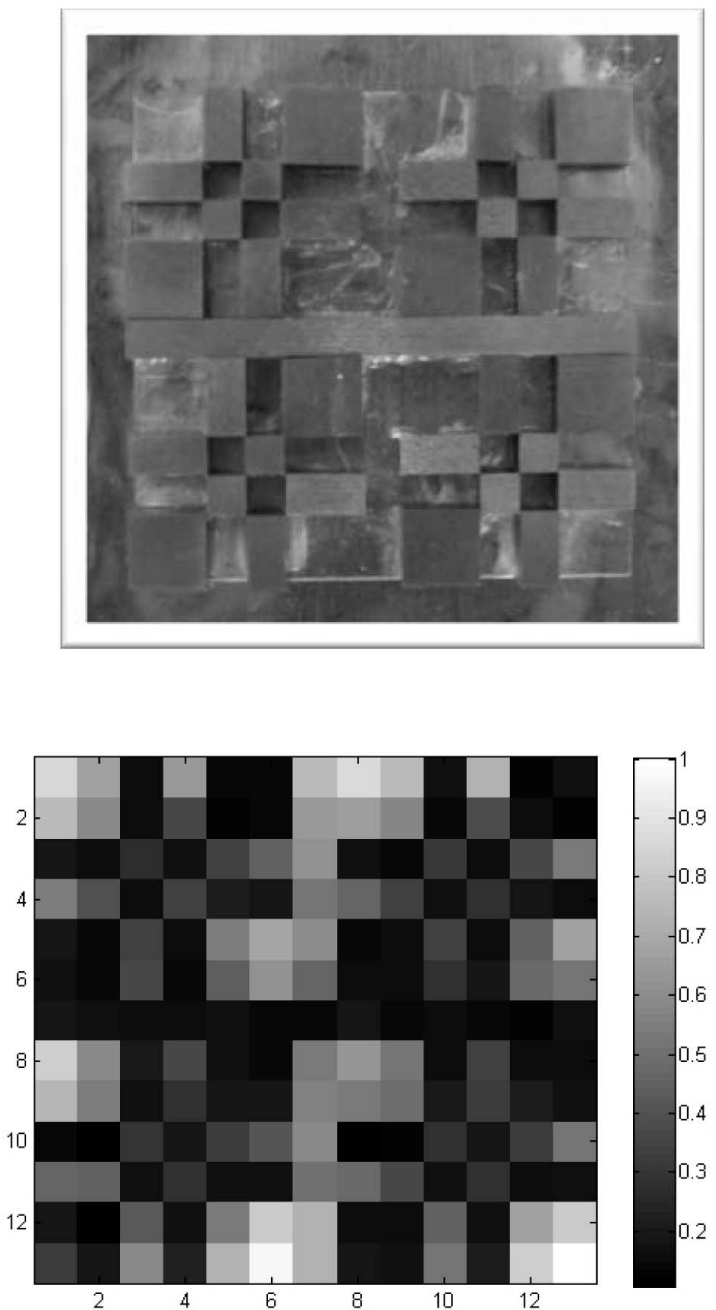

Fig. 5. Photographs of the Experiment and 2D XRF Images of a Mixed Material: (a) Detector and Source Movement, (b) Patterned Tungsten on a Lead Plate, (c) Relative Kal-line Intensity of Tungsten, and (d) Relative Kal-line Intensity of Lead 

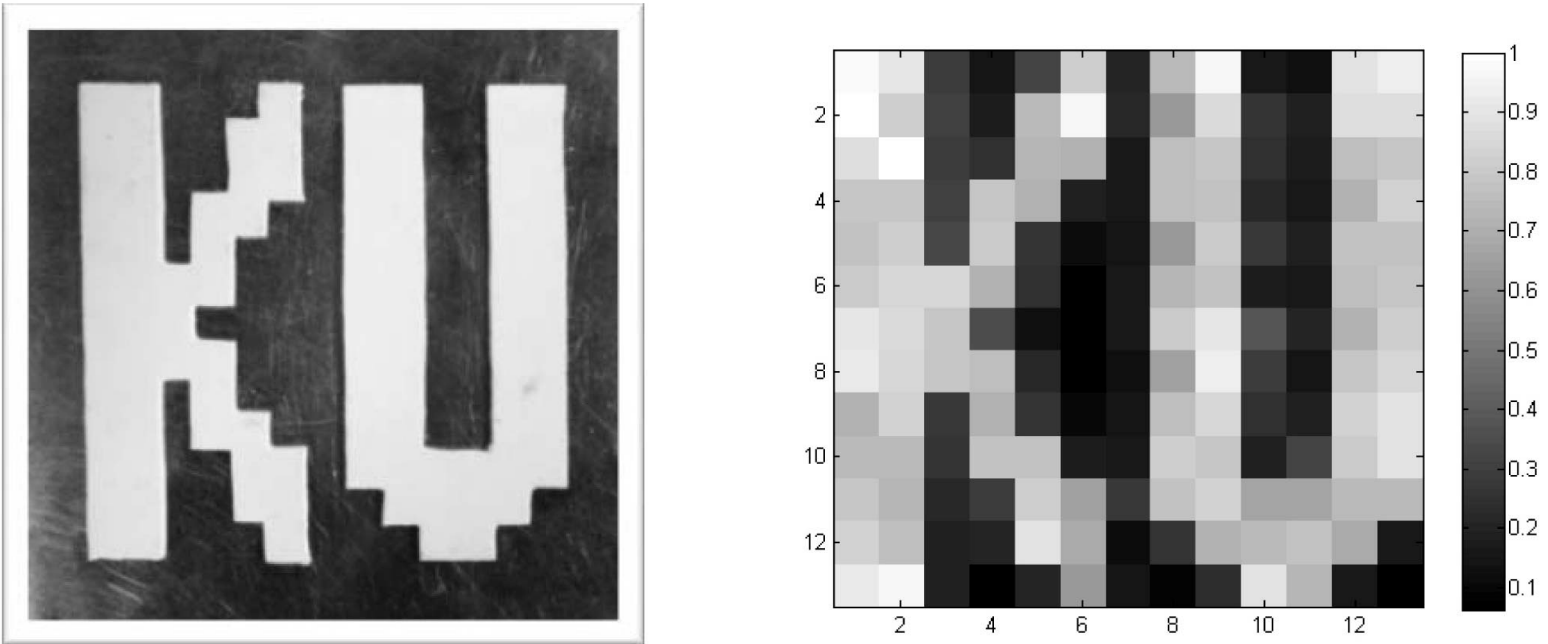

Fig. 6. Photograph and 2D XRF Image of Bi Characters on an Al plate: (a) Two Bi Characters on an Al Plate and (b) Relative $\mathrm{K}_{\alpha 1}$-line Intensity of $\mathrm{Bi}$

materials were clearly separated from each other. Fig. 6 shows a photo and a 2D XRF image of a Bi character on an Al plate. While the distribution of Bi was clearly reconstructed, that of the $\mathrm{Al}$ plate could not be analyzed because, for light elements $(Z<20)$, the dominant product of $\mathrm{K}$ shell ionization is Auger electrons rather than characteristic X-rays, and the Al transition energies are similar to the ${ }^{57} \mathrm{Co}$ radiation energy [2]. The scanning time for each step was 60 seconds, and the total scanning time was approximately 3 hours.

\section{CONCLUSIONS}

The XRF spectrum and distribution of mixed materials were obtained. The simulation and experimental results for the XRF spectrum were well matched with the theoretical values $(<0.61 \%)$. In the case of a mixed material, some of the XRF peaks were overlapped by energy broadening and a tail effect, which prevented spectral analysis. The 2D XRF distributions were obtained by scanning a detector and a source over the mixed materials. A 2D image of the tungsten patterns on a lead plate was clearly reconstructed. A Bi character was highly discernable on an Al plate. However, the $X R F$ radiation from the Al plate could not be distinguished from the radiation coming directly from the ${ }^{57}$ Co source.

\section{ACKNOWLEDGMENT}

This study was supported by Nuclear Research \& Development Program of National Research Foundation of Korea (NRF) funded by Ministry of Education, Science \& Technology (MEST).

\section{REFERENCES}

[1] K. Janssens, G. Vittiglio, I. Deraedt, A. Aerts, B. Vekemans, L. Vincze, F. Wei, I. Deryck, O. Schalm, F. Adams, A. Rindby, A. Knoechel, A. Simionovici and A. Snigirev, "Use of Microscopic XRF for Non-destructive Analysis in Art and Archaeometry", X-Ray Spectrometry, 29, 73. (2000)

[2 ] K. Janssens and R. V. Grieken, "X-ray based methods of analysis: Comprehensive Analytical Chemistry XLII, p.129, Elsevier, Amsterdam. (2004)9

[3] T. Takahashi and S. Watanabe, "Recent Progress in CdTe and CdZnTe Detectors", Transaction on Nuclear Science, 48, 4. (2001)

[4] T. Takahashi, K. Hirose, C. Matsumoto, K. Takizawa, R. Ohno, T. Ozaki, K. Mori, and Y. Tomita, "Performance of a new Schottky CdTe detector for hard X-ray spectroscopy," in Proc. SPIE, 3446, 29. (1998)

[ 5 ] C. Matsumoto, T. Takahashi, K. Takizawa, R. Ohno, T. Ozaki, and K.Mori, "Performance of a new Schottky CdTe detector for hard X-ray spectroscopy," IEEE Transaction on Nuclear Science., 45, 428. (1998)

[6] T. Takahashi, B. Paul, K. Hirose, C. Matsumoto, R. Ohno, T. Ozaki, K. Mori, and Y. Tomita, "High-resolution Schottky CdTe diode for hard X-ray and gamma-ray astronomy," Nucl. Instrum. Meth., A436, pp. 111-119, (1999)

[ 7 ] K. O. Kim, J. K. Kim, J. H. Ha and S. Y. Kim, “Analysis of Charge Collection Efficiency for a Planar CdZnTe Detector," Nucl. Eng. Technol., 41, 5 (2009)

[8 ] R. Robert, "Charge Trapping in XR-100T-CdTe and CZT Detectors", ANCZT, 2, 3. (2007) 
[9] D. D. Richard and G. K. Ernest, X-ray transition energies: new approach to a comprehensive evaluation. Riview of modern physics, 75, 1. (2003)

[10] P. Indelicato, S. Boucard, and E. Lindroth, "Relativistic and many-body in $\mathrm{K}, \mathrm{L}$, and $\mathrm{M}$ shell ionization energy for elements with $10 \mathrm{Z} 100$ and the determination of the $1 \mathrm{~s}$ Lamb shift for heavy elements." The European Physical Journal, D3, 29. (1998) 